\title{
ANALISIS KEUNTUNGAN DAN PEMASARAN BENIH IKAN BAWAL DI BELITANG KABUPATEN OKU TIMUR
}

\author{
(Hariyono)
}

\begin{abstract}
The purpose of this research were to: (1) Determine the seed marketing strategy pomfret in District Belitangr when seen from the SWOT descriptive analysis, (2) analyzing the pomfret fish hatchery operations in the District Belitang advantageous in one production process. This research was conducted in the District OKU Belitang East District. This research was conducted in the District Belitang. Determining the location of the research done by purposive or deliberate, with the consideration that in one of the District who developed hatchery operations and market pomfret pomfret fish fry as well as the region has a considerable number of the population in the study criteria. Location data collection research has been conducted on the Moon May 2015 until completion. This study found that profits in the business pomfret fish hatchery gained acceptance $R p$ 20,305,551 and $R p$ 12,305,449 earned income of $R$ / C in the hatchery operations pomfret at $2: 50$ this value is greater than 1 means that each $R P 1$ spent will get the reception is 2.50 and the $B / C 1: 50$ this value is greater than zero, which means each RP 0 then it will get revenue of 1.50 so that the analysis value of $R$ / C to $B$ / C can be concluded that hatchery operations pomfret get scope for further gains.
\end{abstract}

Key Words : Colossoma macroponum, Management Strategy, income.

\section{PENDAHULUAN}

\section{A. Latar Belakang}

Komoditas perikanan yang memiliki prospek yang baik untuk dikembangkan sebagai ikan budidaya, salah satunya ikan bawal air tawar (Colossoma macropomu). Kelebihan ikan bawal ini antara lain ukuran badannya yang cukup besar, dagingnya gurih dan tidak banyak duri. Sedangkan dari sisi rasa, ikan bawal air tawar tidak kalah lezat dibanding ikan bawal air laut. Selain pertumbuhannya cepat, kelebihan lain ikan bawal adalah cara memeliharanya sulit. Ikan ini dapat dipelihara di kolam dengan tingkat kelangsungan hidup dan padat tebar yang tinggi. Ikan bawal yang dipelihara dalam kolam pendederan dan pembesaran kelangsungan hidupnya dapat mencapai 90 persen. Ikan bawal air tawar memiliki keunggulan daripada ikan bawal air laut, karena produksinya tidak terpengaruh oleh musim, ketersediaan benih dan ikan yang siap konsumsi kontinyuitasnya terjamin dan tersedia sepanjang waktu (Yasin dan Harman, 2014).

Peningkatan produksi budidaya akan meyebabkan peningkatan permintaan benih sebagai input untuk kegiatan budidaya pembesaran ikan bawal dan konsumsi rumah tangga. Produksi ikan bawal pada saat ini sangat pesat, karena usaha ini berada dalam tahap pertumbuhan sehingga permintaan dan produksinya selalu mengalami kenaikan. Permintaan ikan bawal air tawar juga selalu mengalami peningkatan secara nasional (Yasin dan Harman, 2014).

Suatu kondisi yang semakin memantapkan posisi sektor perikanan sebagai penghasil devisa bagi Indonesia, yakni permintaan terhadap produk perikanan dari tahun ke tahun semakin meningkat. Hal ini disebabkan oleh adanya pergeseran konsumsi masyarakat dunia dari red meat menjadi white meat, setelah merebaknya berbagai penyakit hewan, seperti; penyakit mulut, kuku, dan antraks, serta flu burung. Selain itu, ada kecenderungan volume dan nilai ekspor perikanan Indonesia dari tahun ke tahun semakin meningkat disebabkan harganya produk/komoditas ikan di pasar dunia juga semakin meningkat. Menurut data lembaga pangan PBB (FAO, dalam Republika 2005), bahwa Indonesia merupakan produsen ikan terbesar keenam di dunia dengan volume produksi enam juta ton pertahun, bersumber dari berbagai daerah.

Sentra perikanan budidaya air tawar Provinsi Sumatera Selatan berada di beberapa kabupaten yaitu kabupaten Musi Rawas. Mulai dari budidaya kolam, karamba, jaring apung dan minapadi ada di kabupaten ini. Bahkan menjadi penghasil terbesar pada setiap jenis budidayanya kecuali budidaya jaring apung. Selain Musi Rawas, sentra budidaya air tawar terdapat pula di OKU Timur, Lubuk Linggau, Pagaralam, Lahat, OKU dan OKU Selatan.

Produksi perikanan budidaya air tawar Provinsi Sumatera Selatan termasuk stabil. Produksinya setiap tahun mengalami peningkatan. 
Sempat disalip produksi oleh Sumatera Barat pada tahun 2008 namun di tahun selanjutnya Sumatera Selatan tetap yang nomor satu di pulau Sumatera. Pada Tahun 2009 produksi perikanan budidaya air tawar mencapai $110.390,5$ ton dan pada tahun 2010 sebesar $151.927,7$ ton. Berdasarkan data produksi perikanan di provinsi Sumatera Selatan sebagai mana pada tabel 1 berikut ini :

Tabel 1. Produksi Perikanan Kabupaten/Kota di Sumatera Selatan.

\begin{tabular}{|c|c|c|c|c|c|}
\hline \multirow{3}{*}{ No } & \multirow{3}{*}{ Kab/Kota } & \multicolumn{3}{|c|}{ Produksi(Ton) } & \multirow[b]{3}{*}{ Budidaya } \\
\hline & & \multicolumn{3}{|c|}{ Perikanan Tangkap } & \\
\hline & & Laut & $\begin{array}{l}\text { Peraiaran } \\
\text { Umum }\end{array}$ & Total & \\
\hline 1 & Palembang & - & 1.510 .70 & 1.510 .70 & 8.057 .40 \\
\hline 2 & Musi Banyuasin & - & 8.099 .20 & 8.099 .20 & 8.247 .00 \\
\hline 3 & Banyu Asin & 33.817 .90 & 9.117 .60 & 42.935 .50 & 11.301 .20 \\
\hline 4 & Ogan Komering Ilir & 7.058 .80 & 9.868 .50 & 16.927 .30 & 72.516 .60 \\
\hline 5 & Ogan Ilir & - & 4.182 .20 & 4.182 .20 & 10.293 .80 \\
\hline 6 & Ogan Komering Ulu & - & 4.278 .90 & 4.278 .90 & 11.066 .50 \\
\hline 7 & OKU Timur & - & 1.427 .50 & 1.427 .50 & 15.763 .20 \\
\hline 8 & OKU Selatan & - & 1.222 .70 & 1.222 .70 & 10.940 .00 \\
\hline 9 & Muara Enim & - & 4.705 .90 & 4.705 .90 & 4.872 .40 \\
\hline 10 & Prabumulih & - & 482.40 & 482.40 & 2.352 .70 \\
\hline 11 & Musi Rawas & - & 1.801 .00 & 1.801 .00 & 21.371 .90 \\
\hline 12 & Lubuk Linggau & - & 241.60 & 241.60 & 15.707 .80 \\
\hline 13 & Lahat & - & 2.527 .30 & 2.527 .30 & 10.043 .50 \\
\hline
\end{tabular}

Sumber : Dinas Kelautan dan Perikanan Sumatera Selatan, 2010.

Wilayah penghasil larva benih ikan patin, lele, bawal, gurami dan nila seperti Balai Benih Ikan Provinsi Sumatera Selatan selain Musi Rawas sebagai sentra budidaya air tawar terdapat pula di OKU Timur, Lubuk Linggau, Pagaralam, Lahat, OKU dan OKU Selatan sebagai sentra pembenihan ikan di Sumatera Selatan.

Salah satu wilayah penghasil larva atau benih ikan bawal di Sumatera Selatan adalah wilayah Kabupaten OKU Timur. Meningkatnya produksi budidaya perikanan terutama di Kabupaten OKU Timur, juga meningkatkan permintaan akan benih sehingga membuka peluang usaha yang lebih besar di usaha pembenihan ikan. Berdasarkan permintaan benih Ikan di Kabupaten OKU Timur mengalami peningkatan terutama benih ikan bawal. Meningkatnya permintaan benih ikan bawal juga akan meningkatkan permintaan larva ikan bawal sebagai input untuk kegiatan pembenihan. Peningkatan tersebut memberikan dampak positif yaitu terbentuknya peluang pasar yang lebih luas dengan harga yang cukup bersaing. Ditinjau dari aspek pemasaran terutama pertimbangan pemasaran benih ikan bawal di Kabupaten OKU
Timur, memilih wilayah sekitar Kabupaten OKU Timur sebagai pasar utama untuk memasarkan benih ikan bawal merupakan tindakan yang realistis.

\section{B. Rumusan Masalah}

1. Bagaimana strategi pemasaran benih ikan bawal di Kabupaten OKU Timur jika dilihat dari kekuatan, kelemahan, peluang, dan ancaman pada pemasaran ikan bawal.

2. Apakah Usaha Pembenihan ikan bawal di Kecamatan Belitang Menguntungkan dalam satu lali proses produksi.

\section{Tujuan dan Kegunaan}

1. Mengetahui strategi pemasaran benih ikan bawal di Kecamatan Belitangr jika dilihat dari analisis deskriptif SWOT.

2. Menganalisis usaha pembenihan ikan bawal di Kecamatan Belitang menguntungkan dalam satu kali proses produksi.

\section{Model Pendekatan}

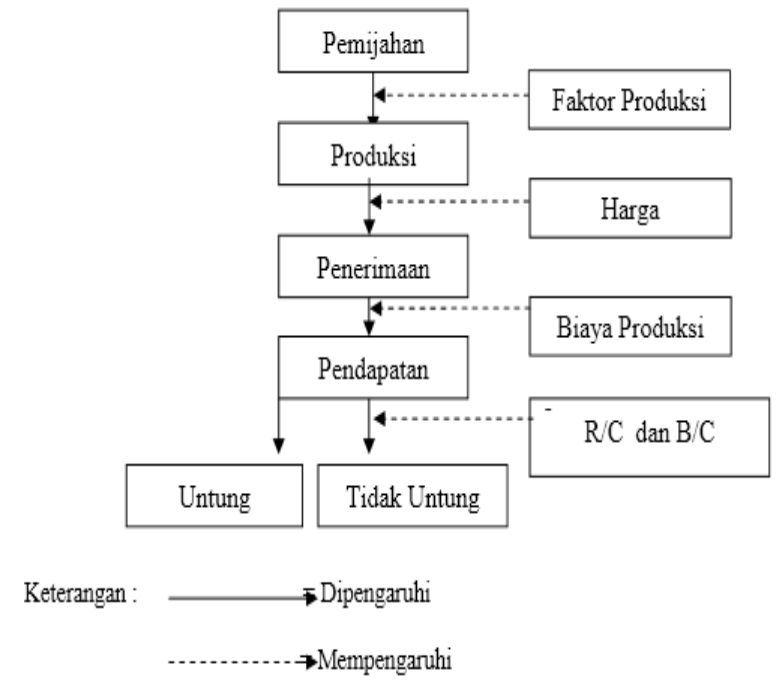

Gambar 1. Model pendekatan penelitian secara diagramatik

\section{METODOLOGI PENELITIAN}

\section{A. Tempat dan Waktu}

Penelitian ini dilakukan di Kecamatan Belitang. Penentuan lokasi penelitian dilakukan secara purposive atau sengaja, dengan pertimbangan bahwa di salah satu Kecamatan yang mengembangkan usaha pembenihan ikan bawal dan memasarkan benih ikan bawal serta wilayah tersebut memiliki jumlah populasi yang cukup dalam kriteria penelitian. Pengumpulan 
data dilokasi penelitian Telahn dilaksanakan pada Bulan Mei 2015 sampai dengan selesai.

\section{B. Metode Penelitian}

Metode yang digunakan dalam penelitian ini adalah metode survei. Metode survei adalah penyelidikan yang diadakan untuk memperoleh fakta-fakta dari gejala-gejala yang ada dan mencari keterangan-keterangan secara faktual. Metode ini digunakan untuk mengetahui berapa besar biaya pada usahatani pembesaran ikan bawal yang digunakan petani berdasarkan data yang didapatkan dari petani sampel.

\section{Metode Penarikan Contoh}

Penelitian ini menggunakan dua macam metode pengambilan data yaitu data primer dan data sekunder. Data primer adalah data yang diperoleh sendiri dengan melakukan pengamatan secara langsung ke lokasi penelitian;

1. Pengamatan yakni melakukan peninjauan langsung dan melakukan pengamatan pada objek penelitian untuk mengidentifikasi masalah-masalah yang dihadapi pada Usaha pemijahan dan sistem pemasaran di Kabupaten OKU Timur

2. Wawancara yakni melakukan pengumpulan informasi khusunya terkait dengan strategi pemasaran ikan bawal. Wawancara dilakukan pada sejumlah pekerja dan pimpinan usaha pemijahan ikan bawal.

Data sekunder adalah data yang diperoleh atau dikumpulkan oleh pihak lain, dapat bersumber dari pustaka dan lembaga yang terkait dengan penelitian ini. Data sekunder yang dikumpulkan Dokumentasi yakni membaca berbagai literatur dan bahan referensi lainnya yang berhubungan erat dengan penelitian ini.

\section{Metode Pengolahan Data}

\section{Analisis Deskriptif Kualitatif}

Analisis deskriptif kualitatif digunakan untuk mengidentifikasi faktor internal dan eksternal yang menjadi kekuatan, kelemahan, peluang dan ancaman dalam sistem agribisnis pemasaran ikan bawal di Kecamatan Belitang Kabupaten OKU Timur.

\section{Matrik SWOT}

Analisis SWOT digunakan untuk mengidentifikasi dan menganalisis faktor-faktor strategis sistem agribisnis pembenihan ikan bawal baik secara internal (kekuatan, kelemahan) maupun eksternal (peluang, ancaman) dalam kondisi saat ini kemudian berusaha membandingkan antara faktor internal kekuatan kelemahan dengan faktor eksternal peluang ancaman. Lingkungan internal yang dianalisis meliputi kondisi keuangan, sumber daya manusia, pemasaran, prouksi/operasional, dan manajemen. Sedangkan lingkungan eksternal yang dianalisis meliputi kondisi perekonomian, sosial budaya, pemerintah, teknologi, persaingan dan cuaca.

Untuk merumuskan alternatif strategi pengembangan pemasaran ikan bawal di Kabupaten OKU Timur. Digunakan analisis Matriks SWOT. Matrik SWOT dapat menggambarkan secara jelas bagaimana peluang dan ancaman eksternal yang dihadapi suatu usaha sehingga dapat disesuaikan dengan kekuatan dan kelemahan yang dimilikinya. Matrik ini dapat menghasilkan empat sel kemungkinan alternatif strategi, yaitu strategi S-O, strategi W-O, strategi W-T, dan strategi S-T.

3. Untuk menghitung biaya produksi pada usaha pemijahan Ikan Bawal di Kecamatan Belitang dapat menggunakan rumus matematis sebagi beriku:

$\mathrm{TC}=\mathrm{FC}+\mathrm{VC}$

Keterangan :

$\mathrm{TC}=$ Total Cost $(\mathrm{Rp} /$ Proses Produksi $)$

$\mathrm{FC}=$ Fixed Cost $(\mathrm{Rp} /$ Proses Produksi $)$

$\mathrm{VC}=$ Variable cost $(\mathrm{Rp} /$ Proses Produksi $)$

Untuk menghitung penerimaan dapat menggunakan rumus matetamtis sebagai berikut :

$\mathrm{R}=\mathrm{P} \times \mathrm{Y}$

Keterangan :

$\mathrm{R}=$ Revenue $(\mathrm{Rp} /$ Proses Produksi)

$\mathrm{Y}=$ Yield $(\mathrm{Rp} /$ Proses Produksi)

$\mathrm{P}=$ Price $/$ Harga $(\mathrm{Rp} /$ Proses Produksi)

Dalam menghitung jumlah pendapatan dapat menggunakan rumus matetamtis sebagai berikut:

$\mathrm{I}=\mathrm{TR}-\mathrm{TC}$

Keterangan :

$\mathrm{I}=$ Income/Pendapatan (Rp/Proses Produksi)

$\mathrm{TR}=$ Total Revenue $(\mathrm{Rp} /$ Proses Produksi)

$\mathrm{TC}=$ Total Cost $(\mathrm{Rp} /$ Proses Produksi $)$

Untuk menghitung tingkat Keuntungan Usaha dalam penerimaan digunakan rumus matematis sebagai berikut: 
$\mathrm{R} / \mathrm{C}$ Ratio $=\frac{\mathrm{TR}}{\mathrm{TC}}$

Kriteria:

- Apabila nilai dari $\mathrm{R} / \mathrm{C}>1$, maka usaha tersebut mendapatkan untung,

- Apabila nilai dari $\mathrm{R} / \mathrm{C}<1$, maka usaha tersebut rugi

- Apabila nilai dari $\mathrm{R} / \mathrm{C}=1$, maka usaha tersebut impas (tidak memdapatkan untung maupun rugi). Untuk menghitung tingkat Keuntungan Usaha dalam pendapatan digunakan rumus matematis sebagai berikut:

$\mathrm{B} / \mathrm{C}$ Ratio $=\frac{\mathrm{I}}{\mathrm{TC}}$.

Kriteria:

- Apabila nilai dari $\mathrm{B} / \mathrm{C}>0$, maka usaha tersebut mendapatkan untung,

- Apabila nilai dari $\mathrm{B} / \mathrm{C}<0$, maka usaha tersebut rugi

- Apabila nilai dari $\mathrm{B} / \mathrm{C}=0$, maka usaha tersebut impas (tidak memdapatkan untung maupun rugi).

\section{HASIL DAN PEMBAHASAN}

\section{A. Perumusan Alternatif Strategi Pengembangan Agribisnis Pembenihan Ikan Bawal}

Untuk merumuskan alternatif strategi yang diperlukan dalam mengembangkan usaha pembenihan ikan bawal di Kecamatan Belitang analisis Matriks SWOT. Matriks SWOT menggambarkan secara jelas bagaimana peluang dan ancaman eksternal dapat dipadukan dengan kekuatan dan kelemahan internal sehingga dihasilkan rumusan strategi pengembangan agribisnis pembenihan ikan bawal. Matriks ini menghasilkan empat sel kemungkinan alternatif strategi, yaitu strategi S-O, strategi W-O, strategi W-T, dan strategi S-T. Setelah mengidentifikasi faktor-faktor internal dan eksternal yang menjadi kekuatan dan kelemahan serta peluang dan ancaman dalam mengembangkan agribisnis pembenihan ikan bawal di Kecamatan Belitang, maka diperoleh beberapa alternatif strategi yang dapat dipertimbangkan, antara lain:

\section{a. Strategi S-O}

Strategi S-O (Strength-Opportunity) atau strategi kekuatan peluang adalah strategi yang menggunakan kekuatan internal untuk memanfaatkan peluang eksternal. Alternatif strategi S-O yang dapat dirumuskan adalah :
1. Mempertahankan kualitas produk benih ikan bawal dan meningkatkan kerja sama dengan stakeholder serta mempererat kemitraan untuk mempertahankan kontinuitas produksi dan dapat bertahan di pasaran.

2. Melakukan pengawasan terhadap resiko usaha pembenihan ikan bawal dengan pemerintah.

\section{b. Strategi W-O}

Strategi W-O (Weakness-Opportunity) atau strategi kelemahanpeluang adalah strategi untuk meminimalkan kelemahan yang ada untuk memanfaatkan peluang eksternal. Alternatif strategi W-O yang dapat dirumuskan adalah :

1. Peningkatan pengelolaan usaha pembenihan ikan bawal melalui kerjasama dengan instansi yang terkait dalam rangka menambah daya saing produk benih ikan bawal.

2. Memanfaatkan penyuluhan dan pelatihan dari PPL untuk meningkatkan kemampuan penguasaan teknologi, pengaksesan pasar dan pengelolaan keuangan yang baik.

\section{c. Strategi S-T}

Strategi S-T (Strength-Threat) atau strategi kekuatan-ancaman adalah strategi untuk mengoptimalkan kekuatan internal yang dimiliki dalam menghindari ancaman. Alternatif strategi S-T yang dapat dirumuskan adalah :

1. Mempertahankan dan meningkatkan kualitas produk benih ikan bawal dan menciptakan alternatif sarana produksi yang lebih murah dan ramah lingkungan.

2. Pengelolaan sumber daya alam dan limbah secara maksimal dengan pemerintah dan masyarakat.

\section{d. Strategi W-T}

Strategi W-T (Weakness-Threat) atau strategi kelemahan-ancaman adalah strategi defensif untuk meminimalkan kelemahan internal dan menghindari ancaman eksternal. Alternatif strategi yang dapat dirumuskan:

1. Menigkatkan kualitas sumberdaya petani pemmbenih secara teknik, moral, dan spritual untuk meningkatkan produksi dan daya saing benih ikan bawal

2. Menjalin kerja sama dengan masyarakat sekitar dalam rangka menjaga keharmonisan dan menambah kessempatan kerja

\section{B. Analisis Usaha Pembenihan Ikan Bawal}

\section{Biaya Produksi}

Biaya produksi usaha pembenihan ikan bawal adalah nilai pengorbanan dari berbagai faktor dalam bentuk barang atau jasa yang 
dikeluarkan selama satu proses produksi itu berlangsung. Besarnya biaya yang dikeluarkan akan mempengaruhi pendapatan yang dihasilkan gapoktan karena itu harus ditekan seminimal mungkin biaya yang dikeluarkan (Soekartawi, 2011).

Dalam penelitian biaya yang dikeluarkan oleh responden terdiri dari biaya tetap dan biaya variabel. Biaya tetap yang dikeluarkan dalam pembenihan ikan bawal terdiri dari biaya sewa tempat dan biaya penyusutan alat sedangkan biaya variabel yang dikeluarkan yaitu pembelian bahan baku, biaya listrik dan upah tenaga kerja. Untuk lebih jelasnya rincian biaya produksi usaha pembenihan ikan bawal dapat dilihat pada tabel dibawah ini.

Tabel 2. Biaya Produksi rata- rata yang dikeluarkan dalam Pembenihan Ikan Bawal.

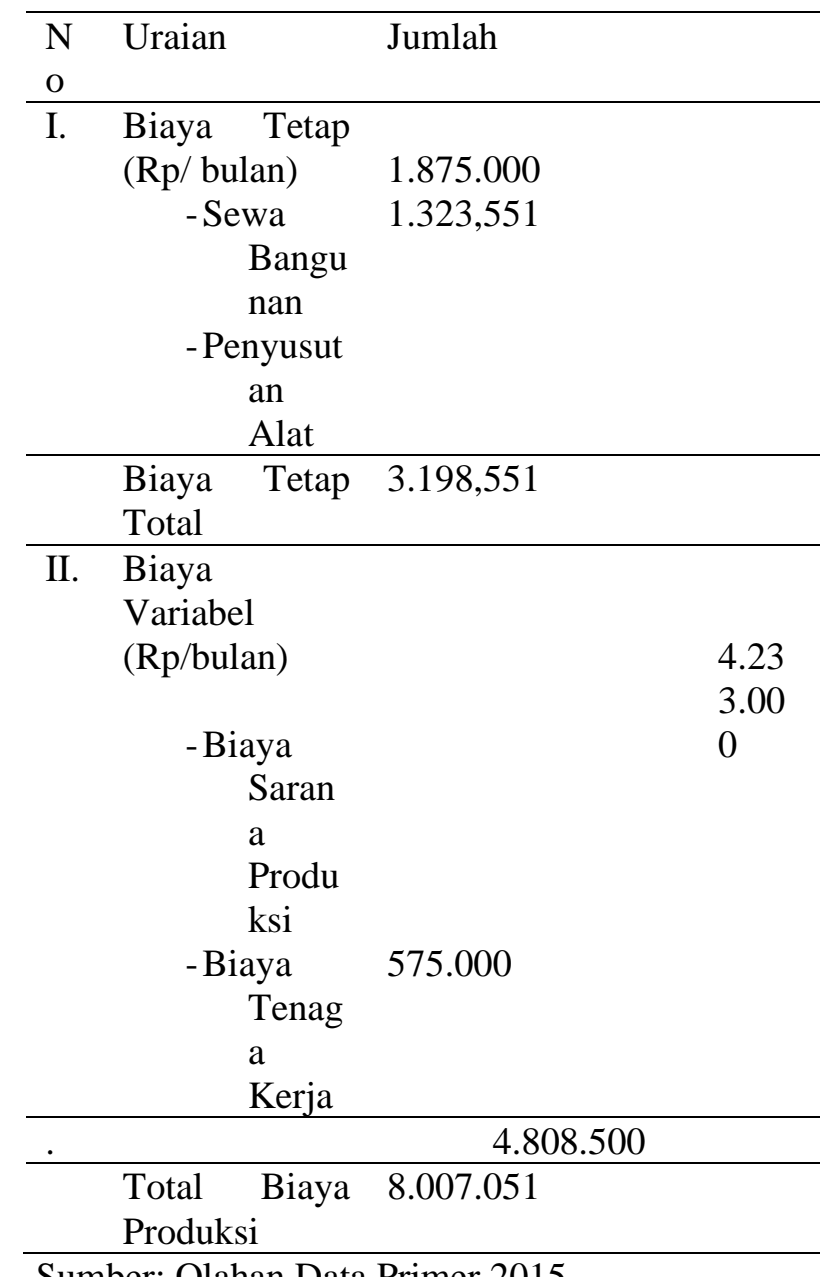

Sumber: Olahan Data Primer,2015.

Berdasarkan tabel di atas, dapat diketahui bahwa biaya produksi rata- rata yang dikeluarkan dalam pembenihan ikan bawal sebesar Rp. $8.007,051 /$ proses dalam satu kali proses produksi yang terdiri dari biaya tetap dan biaya variabel.
Biaya tetap rata-rata pada usaha pemijahan ikan bawal memerlukan biaya $\mathrm{Rp}$ 3.198.551/proses, yang meliputi biaya sewa tampat dan biaya penyusutan alat biaya sewa bangunan memerlukan biaya dengan rata-rata penggunaan sebesar $\mathrm{Rp}$ 1.875.000/proses produksi dan biaya penyusutan alat memerlukan biaya $\mathrm{Rp} 1.323,551$, proses produksi yang meliputi penggunaan alat seperti akuarium bak pemijahani dengan terpal.

Biaya Variabel rata-rata yang habis dalam satu kali proses produksi, pada usaha pembenihan ikan bawal Biaya variabel sebesar Rp 4.808.500/proses, yang meliputi biaya sarana produksi dan biaya tenaga kerja, dapat diketahui bahwa jumlah dari biaya rata-rata sarana produksi dalam usaha tersebut adalah Rp 4.233.000/proses produksi meliputi rata-rata biaya pembelian ovaprim artemia. Plastik packing sampai dengan biaya transportasi dan biaya lain-lain.

Biaya tenaga kerja yang digunakan dalam proses pembenihan ikan bawal adalah $\mathrm{Rp}$ 575.000/proses produksi. Menurut responden tenaga yang digunakan untuk tenaga kerja yang digunakan adalah tenaga kerja harian kerja pria (HKP) dengan upah harian. Jumlah 2-5 orang yang digunakan dalam beberapa kegiatan diantaranya pada pembrsihan bak pemijahan, proses pemijahan, pembersihan kotoran larva, dan packing larva.

\section{Produksi ,Penerimaan dan Pendapatan Usaha Pembenihan Ikan Bawal}

Sugiyanto, 2002 mengemukakan bahwa produksi adalah proses yang dilakukan oleh perusahaan atau produsen berupa kegiatan mengkombinasikan input (sumber daya) untuk menghasilkan output. Dengan demikian produksi merupakan proses transformasi (perubahan) dari input menjadi output. Dalam jangka pendek perusahaan atau produsen memilih input tetap dan menentukan berapa banyaknya input variabel yang harus digunakan. Untuk membuat keputusan pengusaha/petani akan memperhitungkan seberapa besar dampak penambahan input variabel terhadap produksi total. Penambahan input dapat tetap berlangsung sampai batas produk marginal maksimal, dan akan dihentikan jika penambahan produksi menurun. 
Tabel 3. Rata-rata Pendapatan Usaha Pembenihan Ikan Bawal.

\begin{tabular}{|c|c|c|c|}
\hline No. & Uraian & Satuan & Jumlah \\
\hline 1. & Produksi & Ekor & 162.500 \\
\hline 2. & Harga & Rp/Ekor & 125 \\
\hline 3. & Penerimaan & $\begin{array}{l}\text { Rp/proses } \\
\text { produksi }\end{array}$ & 20.312 .500 \\
\hline 4. & $\begin{array}{l}\text { Biaya } \\
\text { produksi }\end{array}$ & $\begin{array}{l}\text { Rp/proses } \\
\text { produksi }\end{array}$ & 8.007 .051 \\
\hline 5. & Pendapatan & $\begin{array}{l}\text { Rp/proses } \\
\text { produksi }\end{array}$ & 12.305 .449 \\
\hline
\end{tabular}

Sumber : Olahan Data Primer, 2015.

Produksi dalam kegiatan usaha pembenihan ikan bawal adalah jumlah produk yang dihasilkan dari usaha pembenihan ikan bawal dalam bentuk harga akhir pembenihan ikan bawal dan harga yang telah ditetapkan oleh dinas perikanan. Usaha pembenihan ikan bawal dalam satu kali proses produksi yaitu hasil akhir pemijahan bawal yang disebut dengan harga akhir dengan harga Rp. 125/ekor dalam satu kali proses produksi.

Penerimaan adalah jumlah dari produksi pada usaha pembenihan ikan bawal dihasilkan responden dikalikan dengan harga jual yang berlaku. Dalam satu kali proses produksi, penerimaan responden dengan rat-rata produksi 162.500 ekor ikan bawal rata-rata penerimaan responden yaitu $\mathrm{Rp} 20.312 .500 /$ proses produksi usaha pembenihan ikan di Kecamatan Belitang sebesar rata-rata biaya produksi yang digunakan Rp 8.007.051/proses produksi. Dilihat dari penerimaan yang diperoleh responden pembenihan ikan dapat diketahui bahwa penerimaan lebih besar dari pada biaya produksi yang dikeluarkan. Pendapatan merupakan selisih antara jumlah dari penerimaan dengan biaya produksi usaha pembenihan ikan bawal. Rata rata pendapatan usaha pembenihan ikan bawal adalah Rp 12.305.449/proses produksi.

\section{Analisis Keuntungan Usaha}

Tingkat keuntungan pada usaha pembenihan ikan bawal di Kecamatan Belitang diukur menggunakan tingkat keuntunan $\mathrm{R} / \mathrm{C}$ dan $\mathrm{B} / \mathrm{C}$ yang bertujuan untuk mengetahui tingkat kelayakan usaha pembenihan ikan bawal berdasarkan olahan data primer pada tingkat kelayakan usaha pada tabel berikut :

Tabel 4. Nilai Rata-rata R/C ratio Tingkat Keuntungan Usaha Pembenihan Ikan Bawal

\begin{tabular}{lll}
\hline \multirow{2}{*}{ No } & Uji & Tingkat \\
& Keuntungan & \\
\hline 1 & Penenerimaan & 20.312 .500 \\
2 & Biaya Produksi & 8.007 .051 \\
3 & R/C & 2,50 \\
\hline
\end{tabular}

Sumber : Olahan Data Primer, 2015.

Berdasarkan uraian diatas diperoleh pada analisis nilai $\mathrm{R} / \mathrm{C}$ pada usaha pembenihan ikan bawal 2,22.- nilai $\mathrm{R} / \mathrm{C}>1$ dimana sesuai aturan yang telah ditetapkan maka usaha pembenihan ikan bawal dapat dikatakan mengutungkan . dan dapat diartikan seiap Rp 1 biaya yag dikeluarkan maka akan memperoleh penerimaan sebesar 2,50.

Tabel 5. Nilai Rata-rata B/C Ratio Tingkat Keuntungan Usaha Pembenihan Ikan Bawal

\begin{tabular}{lll}
\hline \multirow{2}{*}{ No } & Uji & Tingkat \\
& Keuntungan & \\
\hline 1 & Pendapatan & 12.305 .449 \\
2 & Biaya Produksi & 8.007 .051 \\
3 & B/C & 1,50 \\
\hline
\end{tabular}

Sumber : Olahan Data Primer, 2015.

Nilai B/C Ratio pada usaha pembenihan ikan bawal sebesar 1,22. Nilai ini lebih besar dari 0 artinya bahwa setiap rupiah yang dikeluarkan maka akan memperoleh pendapatan bersih sebesar 1,50. Dengan uraian diatas ( $\mathrm{R} / \mathrm{C}$ dan $\mathrm{B} / \mathrm{C}$ ) Maka usaha pembenihan ikan bawal dapat dikatakan menguntungkan dan layak untuk diteruskan.

\section{IV.KESIMPULAN DAN SARAN}

\section{A. Kesimpulan}

Berdasarnya hasil penelitian dan analisis yang telah dilakukan, maka dapat ditarik kesimpulan sebagai berikut:

1. Kondisi internal (kekuatan dan kelemahan) dan eksternal (peluang dan ancaman) sistem agribisnis pembenihan di Kecamatan Belitang adalah : 
a. Kekuatannya adalah kontinuitas produksi benih, kualitas benih, usaha pembenihan yang mudah dan resiko kecil, organisme pengganggu relatif aman, saprodi mudah di dapat dan potensi SDA yang mendukung.

b.Kelemahannya adalah kemampuan memperoleh teknologi baru masih terbatas, posisi petani pembenih cenderung sebagai penerima harga, pelaksanaan usaha pembenihan kurang optimal, keterbatasan modal dan pengelolaan keuangan petani pembenih kurang baik.

c. Peluangnya adalah meningkatnya permintaan ikan bawal di masyarakat, memiliki hubungan yang baik dengan stakeholder, kondisi lingkungan yang aman, bantuan dari pemerintah, penyuluhan dan pengawasan yang rutin dari PPL.

d.Ancamannya adalah kenaikan harga pakan, tuntutan terhadap penanganan limbah, berkembangnya teknologi pembenihan di daerah lain, harga benih di daerah lain yang lebih murah dan peningkatan pemasaran benih jenis ikan lain.

2. Alternatif strategi yang dapat dikembangkan dalam agribisnis pembenihan ikan di Kecamatan Belitang adalah :

a) Mempertahankan kualitas produk benih dan meningkatkan kerja sama dengan stakeholder mempererat kemitraan.

b) mempertahankan kontinuitas produksi dan dapat bertahan di pasaran,

c) melakukan pengawasan terhadap resiko usaha pembenihan ikan bawal dengan pemerintah.

d) Memanfaatkan penyuluhan dan pelatihan dari PPL untuk meningkatkan kemampuan penguasaan teknologi, pengaksesan pasar dan pengelolaan keuangan yang baik.

e) Pengelolaan SDA secara maksimal dengan pemerintah dan masyarakat,

f) Meningkatkan kualitas sumber daya petani pembenih secara teknis, moral dan spiritual untuk memaksimalkan produksi dan daya saing benih.

g) Menjalin kerja sama dengan masyarakat sekitar dalam rangka menjaga keharmonisan dan menambah kesempatan kerja.

3. Analisis keuntungan pada usaha pembenihan ikan bawal diperoleh penerimaan sebesar Rp 20.305.551 dan pendapatan sebesar $\mathrm{Rp}$ 12.305.449 diperoleh nilai $\mathrm{R} / \mathrm{C}$ pada usaha pembenihan ikan bawal sebesar 2.50 Nilai ini lebih besar dari 1 artinya Setiap RP 1 yang dikeluarkan akan mendapatkan penerimaan sebesar 2,50 dan nilai B/c 1.50 nilai ini lebih besar dibandingkan dengan nol yang artinya setiap RP 0 maka akan mendapatkan pendapatan 1,50 sehingga dengan analisis Nilai $\mathrm{R} / \mathrm{C}$ dengan $\mathrm{B} / \mathrm{C}$ diatas dapat disimpulkan bahwa usaha pembenihan ikan bawal mendapatkan keuntungan layak untuk diteruskan.

\section{B. Saran}

Saran yang dapat diberikan dari hasil penelitian yang telah dilakukan adalah:

1. Petani pembenih sebaiknya lebih mempererat kemitraan dengan stake holder (kelompok pembenihan) misalnya dengan mengadakan pertemuan rutin antar anggota, karena kelompok tani ikan ini sebagai wadah dari petani pembenih yang merupakan sarana berbagi pengalaman dan pengetahuaan antar pembenih serta merupakan tempat petani untuk mendapatkan akses yang lebih besar untuk bekerjasama dengan pemerintah.

2. Pemerintah diharapkan lebih aktif dalam memberdayakan penyuluh untuk meningkatkan motivasi petani pembenih dalam mengusahakan pembenihan ikan bawal, dengan memberikan pelatihan teknis budidaya Pemerintah diharapkan lebih aktif dalam memberdayakan penyuluh untuk memberikan informasi tentang pemberian pakan dan penanganan penyakit untuk menekan angka kematian benih ikan bawal, sehinga diharapkan produksi dapat meningkat dan permintaan benih ikan bawal di masyarakat dapat terpenuhi.

\section{DAFTAR PUSTAKA}

Assauri. 2006. Manajemen Produksi dan Operasi. Fakultas Ekonomi Universitas Indonesia. Jakarta

Dahuri, R, 2002, Membangun Kembali Perekonomian Indonesia Melalui Sektor Perikanan dan Kelautan, Jakarta, LISPI.

Hanafie, R. 2010. Pengantar Ekonomi Pertanian. CV. Andi Offset. Yogyakarta

Kusnadi. 2006. Study Kelayakan Bisnis. Universitas Brawijaya. Malang.

Lamb.Charles, W, 2001, Pemasaran. Salemba Empat, Jakarta. 
Moesher, AT. 2000. Menggerakkan dan Membangun Pertanian. Syarat-syarat Pokok Pembangunan dan Modernisasi. Departemen Pertanian. Jakarta

Muhammad, Suwarsono, 2008, Manajemen Strategi; Konsep dan Kasus. Unit Penerbitdan Percetakan, Sekolah Tinggi Ilmu Manajemen YKPN. Yogyakarta.

Rangkuti, Freddy, 1997, Analisis Swot; Teknik Membedah Kasus Bisnis. Gramedia Pustaka Umum. Jakarta.
Wicaksana, E.A., 2003, Analisis Strategi Pemasaran Produk Perikanan (Udang Windu) PT. Inti Aquatiq Perdana”. Universitas Hasanuddin Makassar, Tesis Tidak Dipublikasikan. Diakses 15 Februari 2015

Yasin, M dan Harman. 2014. Jurnal Ilmiah AgrIBA No2. Analisis Strategi Pemasaran Komoditas Perikanan (Ikan Bawal) CV. Hasnidar di Pulau Sebatik Kabupaten Nunukan Provinsi Kalimantan Utara. Diakses pada 15 Februari 2015. 